\title{
Hexacyanoferrate(III) Transport in Coated Montmorillonite Clay Films. Effects of Water-Soluble Polymers
}

\author{
J ean-Marie Séquaris \\ Institute of Applied Physical Chemistry (ICG 7), Research Centre J ülich, P.O. Box 1913, \\ D-52425 J ülich, Germany
}

Received May 7, 1999. In Final Form: August 16, 1999

\begin{abstract}
Hexacyanoferrate(III) Fe(CN) $6^{3-}$, transport through coated montmorillonite clay films at a platinum electrode is studied with the cyclic voltammetric method. Experimental conditions are first established guaranteeing voltammetric detection based on a linear diffusion in the clay film. The square of the ratio $\left(R^{2}\right)$ of current intensities obtained at the clay modifed el ectrode (CME) and the bare Pt el ectrode measures the relative variation of the $\mathrm{Fe}(\mathrm{CN})_{6}{ }^{3-}$, diffusion coefficient in the clay film. Thus, the effects of bathing el ectrolyteconcentrations on $\mathrm{R}^{2}$ areinvestigated and related to theswel ling properties of themontmorill onite clay characterized by X-ray diffraction and sedimentation volume results. According to an applied model for the electric conductivity of montmorillonite clay solution, a relationship between the formation factor $F=1 / R^{2}$, the shape factor $(\alpha)$, and the clay film effective porosity $\left(\Phi_{\mathrm{e}}\right)$ is established. The shape factor $(\alpha)$ includes orientation and axial ratio (the ratio (A/B) of the major axis (A) to the minor axis $(B)$ ) parameters which characterize the arrangement of montmorillonite particles in the clay film. The determination of $\Phi_{\mathrm{e}}$ is based on relative variations of the sedimentation volumes. In a salt concentration range from 0.02 to $1 \mathrm{M} \mathrm{NaCl}$, it can be thus proposed that an interparticle $\mathrm{Fe}(\mathrm{CN})_{6^{3-}}$ transport in the clay film is limited by occluded montmorillonite particles with a constant axial ratio. The effects of water-soluble polymers on the shape factor $(\alpha)$, of montmorillonite particles are investigated. At polymer concentrations $\leq 5 \%$ (polymer to montmorillonite, w/w), nonionic poly(vinyl pyrrolidone) (PVP) decreases $\mathrm{Fe}(\mathrm{CN})_{6}{ }^{3-}$ transport in CME while interactions with a low-molecular-weight poly(acrylic acid) (PAA) increases it. The polymer modifications of the clay film can be thus modeled. An aggregation with PVP favors a lateral formation of a band-type network with an increase of the particle axial ratio, i.e., lengthening of the interparticle transport pathway in the clay film. In the case of Iow-molecular-weight PAA, a specific adsorption at the edge of montmorillonite platelets induces an apparent decrease of the particle axial ratio. This can be related to an electrostatic stabilization of clay platelets stacked in a column model, which shortens the interparticle transport pathway in the clay film.
\end{abstract}

\section{Introduction}

The presence of clay minerals in soil or sediments is of considerable significance in the transport mechanisms of nutritients and environmental pollutants. ${ }^{1}$ I ndeed, the colloidal behavior of these anisometric, plate-shaped particles $(<2 \mu \mathrm{m})$, their relatively high surface area, and differential swelling properties ${ }^{2}$ control the fate of dissolved molecular species by adsorption processes at their surfaces or by limiting water transport. Thus, clay films deposited on thesurface of soil por ewalls have been shown to affect ion diffusion. ${ }^{3}$ Clay walls and liners are often used for sealing off waste disposals. ${ }^{4}$

In this regard, the application of cyclic voltammetry $(\mathrm{CV})^{5-14}$ has opened up new approaches in the study of

(1) Parker, A., Rae, J . E., Eds. Environmental Interactions of Clays; Springer: Berlin, 1998.

(2) Lagaly, G. In Surfactant Sciences Series, Vol . 47, Dobiás, B., Ed.; M. Dekker: New York, 1993, Chapter 10. 91.

(3) Chen, S.; Franklin, R. E.; J ohnson, A. D. Soil Science 1997, 162,

(4) Weiss, A. Appl. Clay Sci. 1989, 4, 193.

(5) Ege, D.; Ghosh P. K.; White J. R.; Equey J .-F.; Bard A. J . J . Am. Chem. Soc. 1985, 107, 5644.

(6) Itaya K.; Bard A. J . J . Phys. Chem. 1985, 89, 5565.

(7) Liu H-Y.; Anson F. C. J . Electroanal. Chem. 1985, 184, 411.

(8) Fitch, A. Clays Clay Miner. 1990, 38, 391.

(9) Lee, S. A.; Fitch, A. J . Phys. Chem. 1990, 94, 4998.

(10) Fitch, A.; Du, J ia. J . Electroanal. Chem. 1991, 319, 409.

(11) Subramanian, P.; Fitch, A. Environ. Sci. Technol. 1992, 26, 1775

(12) Fitch, A. In Access in Nanoporous Materials; Pinnavaia, T. J .,

Thorpe, M. F., Eds.; Plenum Press: New York, 1995; p 93.

(13) Stein, J . A.; Fitch, A. Clays Clay Miner. 1996, 44, 381. 2186.

(14) J 00, P.; Fitch, A.; Park, S.-H. Environ. Sci. Technol. 1997, 31 transport mechanism on a $\mu \mathrm{m}$ scale through clay films deposited at an electrode surface. Thus, anionic redox species such as hexacyanoferrate(III $),\left(\mathrm{Fe}(\mathrm{CN})_{6}{ }^{3-}\right)$, which are electrostatically repelled by the negatively charged clay mineral surface, can be used as a conservative electrochemical marker to probethediffusion pathway in clay films coating a platinum electrode. ${ }^{8-14}$ Depending on the time window of the cyclic voltammetric method, monitored by the potential scan rate, it has been demonstrated that an effective diffusion coefficient for $\mathrm{Fe}(\mathrm{CN})_{6}{ }^{3-}$, can be determined inside the clay film of a clay-modified el ectrode (CME). ${ }^{9-10}$ I t foll lows that theratio of the current intensity obtained at a CME and at a bare el ectrodecan beutilized for information about the porous structure of theclay film. ${ }^{9,12}$ Thus, theeffects of thenature and concentration of bathing electrolytes on the CME per meability have been related to the swelling properties of the clay matrix. A direct relation between the clay platelet interlayer dimensions of montmorillonite ${ }^{9}$ and the electrochemical responses can be established. In the case of a nonswelling clay mineral, kaolinite, a diffusive transport of $\mathrm{Fe}(\mathrm{CN})_{6}{ }^{3-}$, between particles or through pinholes in the clay film is suggested..$^{13}$

In this work, the porosity parameter has been further considered in transport modeling by comparing the voltammetric behavior of CME with the swelling dependence of montmorilloniteon theel ectrolyteconcentration. Resul ts from sedimentation vol umeexperiments arethus taken intoaccount in theestimation of an effective porosity of the clay film for $\mathrm{Fe}(\mathrm{CN})_{6}{ }^{3-}$ transport. The axial ratio 
of montmorillonite particles, i.e., the ratio $(A / B)$ of the major axis $(A)$ to the minor axis $(B)$ is also considered in the interpretation where the term "particle" can also designate an aggregation of single montmorillonite platelets.

In the same way, the effects of water-soluble polymers on the diffusional properties of clay films have been also investigated. Indeed, the interactions of natural ${ }^{15,16}$ or syntheti $c^{17-20}$ organic macromol ecules with clay minerals are of great importance in stabilizing the soil structure. Microscopic modifications of the clay mineral particle surface properties by polymers ${ }^{21}$ can affect the stability of the macroscopic soil aggregates through flocculation and dispersion phenomena depending on the polymer nature.

\section{Materials and Methods}

Materials. $\mathrm{K}_{3} \mathrm{Fe}(\mathrm{CN})_{6}$ and poly(acrylic acid) PAA with a molecular weight of $2000 \mathrm{~g} / \mathrm{mol}$ were supplied by Aldrich (Germany). Poly(vinyl pyrrolidone) (PVP) with different mol ecular weights, 5000 (K 12), 44000 (K 30) and 400000 (K80) g/mol was supplied by BASF, (Germany).

Na-montmorillonitel and II wereprepared from Ca-bentonite (Süd-Chemie, Germany). Their cation exchange capacity (CEC) and BET are $98.1 \mathrm{meg} / \mathrm{g}$ and $88.7 \mathrm{~m}^{2} / \mathrm{g}$ for $\mathrm{Na}$-montmorillonite I and $87.5 \mathrm{meq} / \mathrm{g}$ and $95.9 \mathrm{~m}^{2} / \mathrm{g}$ for Na-montmorillonite II respectively. From photon correlation spectroscopy (PCS) measurements, average equivalent spherical hydrodynamic diameters of $0.6 \mu \mathrm{m}$ and $0.45 \mu \mathrm{m}$ arecalculated for $\mathrm{Na}$-montmorillonite I and Na-montmorillonite II respectively in water. Polymermodified montmorillonite suspensions were prepared by adding polymers to a $40 \mathrm{~g} / \mathrm{L} \mathrm{Na-montmorillonite} \mathrm{suspension} \mathrm{up} \mathrm{to} \mathrm{a}$ final concentration of $0.1,0.5,1$, and $2 \mathrm{~g} / \mathrm{L}$. The solutions with added polymer were equilibrated for $65 \mathrm{~h}$ on a horizontal shaker at room temperature.

Methods. Electrochemistry. Voltammetric measurements of $\mathrm{Fe}(\mathrm{CN})_{6}^{3-}$, were performed with a BAS-100A electrochemical analyzer. A Metrohm Pt disk electrode with a diameter of $3 \mathrm{~mm}$ served as the working electrode. A saturated calomel electrode (SCE) was used as a reference electrode and a platinum wire served as the auxiliary electrode. A $20 \mathrm{~mL}$ Metrohm cell thermostated at $20^{\circ} \mathrm{C}$ was employed in these experiments.

Beforeany measurement, thePt-electrodesurface was briefly polished with a wet filter paper onto which some $0.3 \mu \mathrm{m}$ abrasive grains had been sprayed. After rinsing with distilled water, the electrode was then dried by touching the surface with a soft absorbent paper tissue. The quality of the Pt electrode surface was tested by repeating (4 times) cyclic voltammograms from $+0.6 \mathrm{~V}$ to $-0.2 \mathrm{~V}$ (VS SCE) of $4 \mathrm{mM} \mathrm{Fe}(\mathrm{CN})_{6}{ }^{3-}$, dissolved in the bathing electrolyte solution of interest. In the case of a reproducibility of better than $98 \%$, the measured reduction peak current intensity $I_{p_{s 0}}$ was saved for further calculations (see Results section). After rinsing the Pt electrode with distilled water and drying, the clay-modified electrode (CME) was then prepared by transferring $2 \mu \mathrm{L}$ of the Na-montmorillonite water dispersion $(10-40 \mathrm{~g} / \mathrm{L})$ to the surface of the Pt electrode. The coating was allowed to dry by rotating the Pt electrode at $1000 \mathrm{rpm}$ for 30 min. The CME was thus dipped into the electrolyte solution containing $4 \mathrm{mM} \mathrm{Fe}(\mathrm{CN})_{6}{ }^{3-}$, and programmabletime-controlled recording voltammograms from $+0.6 \mathrm{~V}$ to $-0.2 \mathrm{~V}$ (VS SCE) were

(15) Schnitzer, M. In Environmental Impact of Soil Component Interactions; Huang, P. M., Berthelin J ., Bollag, J .-M., McGill, W. B., Page, A. L.; Eds.; CRC Press: Boca Raton, FL, 1995; $\mathrm{p} 3$.

(16) Chenu, C. In Environmental I mpact of Soil Component I nteractions; Huang, P. M., Berthel in J ., Bollag, J .-M., McGill, W. B., Page, A. L., Eds.; CRC Press: Boca Raton, FL, 1995; p 217.

(17) Ben-Hur, M.; Malik, M.; Letey, J .; Mingelgrin, U. Soil Science 1992, 153, 349

(18) Lentz, R. D.; Shainberg, I.; Sojka, R. E.; Carter, D. L. Soil Sci. Soc. Am. J . 1992, 56, 1926.

(19) Ben-Hur, M.; Keren, R. Soil Sci. Soc. Am. J . 1997, 61, 565.

(20) Aase J. K.; Bjorneberg, D. L.; Sojka, R. E. Soil Sci. Soc. Am. J . 1998, 62, 1681 .

(21) Theng, B. K. G. Formation and Properties of Clay-Polymer Complexes, Elsevier: Amsterdam, 1979. generally performed with a potential sweep rate of $0.05 \mathrm{~V} / \mathrm{s}$ during a bathing time of up to 16 min i.e., when no time dependence is observed. At this response time, the corresponding reduction peak current intensities $I_{\mathrm{P}_{\mathrm{CME}}}$ were saved for further cal culations (see Results section).

X-ray Diffraction. X-ray diffraction measurements were performed with with an X-ray diffractometer XRD 3000TT Seifert (Germany). A homemade Pt disk surface of $6 \mathrm{~mm}$ diameter was used as a sample carrier where $20 \mu \mathrm{L}$ of a $40 \mathrm{~g} / \mathrm{L} \mathrm{Na-mont-}$ morillonite water suspension is deposited. As for CME preparation, this removable day-modified Pt disk surface was allowed to rotate at $1000 \mathrm{rpm}$ for $40 \mathrm{~min}$. Under these drying conditions, a clay fim thickness of $6 \pm 1 \mu \mathrm{m}$ can be estimated by microscopy. A well-defined diffraction line at $1.29 \pm 0.04 \mathrm{~nm}\left(\mathrm{~d}_{001}\right)$ was measured by XRD. ${ }^{22-24}$ Effects of electrolyte solutions $0.5,1,2$, and $4 \mathrm{M} \mathrm{NaCl}$ on the $\mathrm{d}_{001}$ diffraction line were observed by the addition of $20 \mu \mathrm{L}$ of the corresponding electrolyte solution. The montmorillonite samples were then covered by a Mylar window film (Spex, US) for XRD analysis.

Sedimentation Vol ume Sedimentation vol umemeasurements were performed by adding the electrolyte solution in a range from 0.02 to $4 \mathrm{M} \mathrm{NaCl}$ in conical $10 \mathrm{~mL}$ vessels containing the preweighted dry montmorillonite (final montmorillonite concentrations were 10,20 , and $40 \mathrm{~g} / \mathrm{L}$ ). The suspensions werefirst equilibrated on a horizontal shaker at room temperature. After a shaking time of $24 \mathrm{~h}$, the sedimentation tubes were then set upright to read the sedimentation volumes for a period of up to six months. The average sedimentation volumes expressed in $\mathrm{cm}^{3} / \mathrm{g}$ were calculated from a linear regression analysis of the results after this period. It must be noted that in the presence of $\mathrm{NaCl}$ concentration $\geq 0.1 \mathrm{M}$, no sedimentation volumevariation can be observed after 3 weeks.

Polymer-modified montmorill onites wereobtained after drying the centrifugates (20000 rpm, $30 \mathrm{~min}$ ) of equilibrated $40 \mathrm{~g} / \mathrm{L} \mathrm{Na}$ montmorillonite suspensions at $60^{\circ} \mathrm{C}$ in the presence of $2 \mathrm{~g} / \mathrm{L}$ polymers.

Photon Correlation Spectroscopy. The photon correlation spectroscopy (PCS) measurements were performed using a Malvern ZetaSizer 4 equipped with a $5 \mathrm{~mW}$ He-Ne laser. Measurements were made at an angle of $90^{\circ}$ with a particle concentration of $0.2 \mathrm{~g} / \mathrm{L}$. The monomodal cumulants method of the ZetaSizer 4 software was used to analyze the correlation function. An averaged translational diffusion constant is thus obtained, from which an equivalent spherical hydrodynamic diameter $\left(\overline{\mathrm{d}}_{\mathrm{z}}\right)$ for the particle is calculated.

Viscosity. Viscometry measurements of Na-montmorillonite were made by using an U bbel ohde type capillary viscometer at $20{ }^{\circ} \mathrm{C}$ (Capillary Type 531 01/0a from Schott, Germany) with automati c measuring equipment (AVS 310) from Schott-Geräte. Flow time readings at three day concentrations $(0.5,0.67$, and $1 \mathrm{~g} / \mathrm{L}$ ) in water were repeated at least 5 times.

The axial ratio $(\mathrm{A} / \mathrm{B})$ of Na-montmorillonite particle, assimilated to oblate spheroids (ellipsoid of revolution about minor axis $B$ with major axis $A \gg B$ ), was calculated from the intrinsic viscosity $[\eta]$ according to the relation ${ }^{25,26}$

$$
[\eta]=\lim _{\varphi \rightarrow 0} \frac{\eta_{\mathrm{sp}}}{\varphi}=\frac{4}{3} \frac{\mathrm{A} / \mathrm{B}}{\tan ^{-1}(\mathrm{~A} / \mathrm{B})} \approx 0.849 \frac{\mathrm{A}}{\mathrm{B}}
$$

where $\eta_{\mathrm{sp}}$ is the specific viscosity. The volume fraction of clay in solution, $\varphi$, is thus defined

$$
\varphi=\left(\frac{\mathrm{C}}{\rho_{\mathrm{c}}}\right)(1+\theta)
$$

where $\rho_{\mathrm{c}}$ is the mass density of the dry clay $\left(2.7 \mathrm{~g} / \mathrm{cm}^{3}\right), \mathrm{c}$ is the 123.

(22) Norrish, K.; Rausell-Colom, J . A. Clays Clay Miner. 1963, 10,

(23) Lagaly, G.; Schön, G.; Weiss, A. Kolloid-Z. u. Z. Polymere 1972, $250,667$.

(24) Slade, P. G.; Quirk, J . P.; Norrish, K. Clays Clay Miner. 1991, $39,234$.

(25) Kahn, A. Clays Clay Miner. 1959, 6, 220.

(26) Dufey, J . E.; Banin, A. Soil Sci. Soc. Am. J . 1979, 43, 782. 

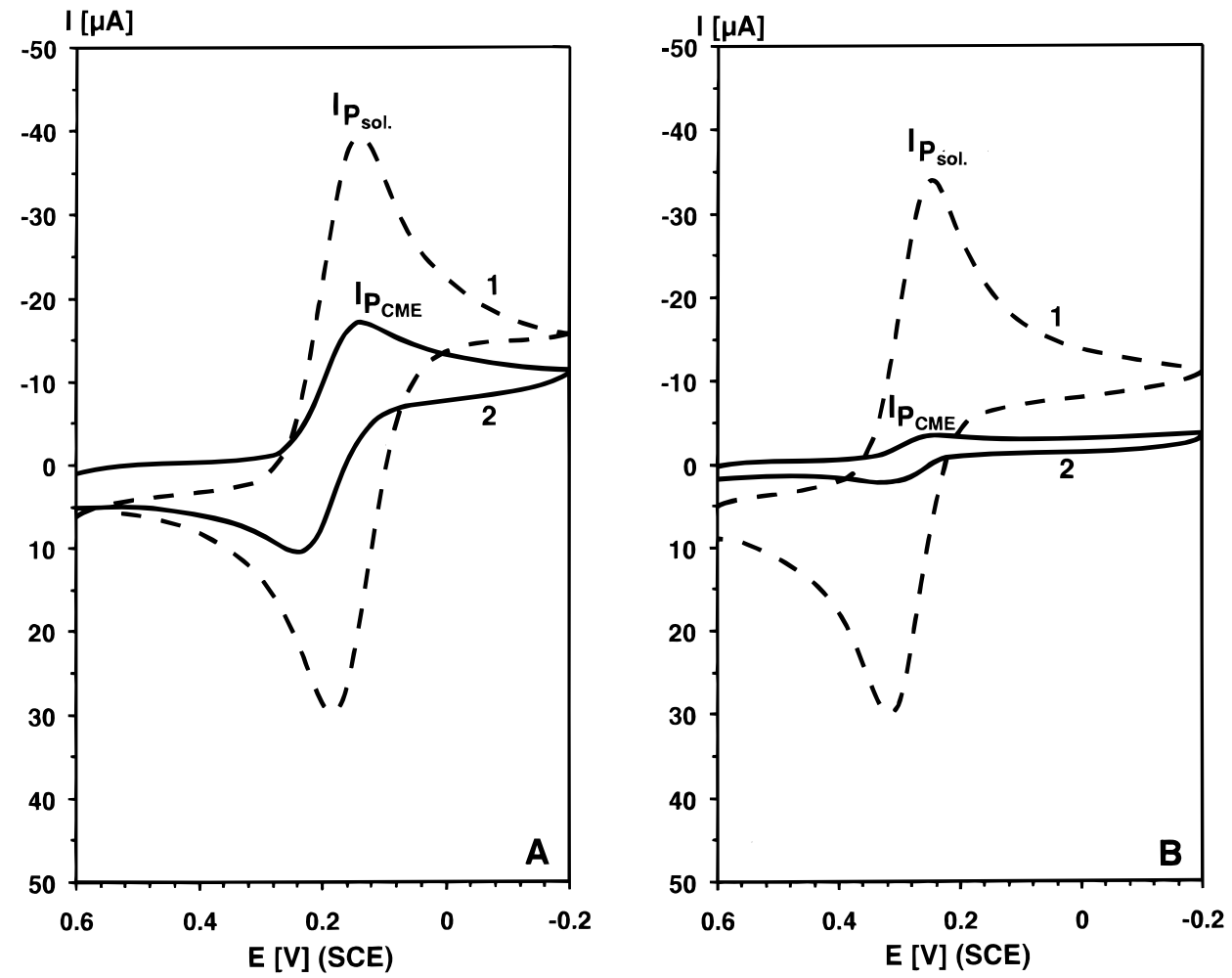

Figure 1. Cyclic vol tammetric responses of $\mathrm{Fe}(\mathrm{CN})_{6}{ }^{3-}$ at montmorillonite clay modified electrode $(\mathrm{CME})$ in $0.2 \mathrm{M} \mathrm{NaCl}(\mathrm{A})$ and $4 \mathrm{M} \mathrm{NaCl}(\mathrm{B})$ solutions. 1: bare Pt electrode; 2: $\mathrm{CME}$; potential scan rate $0.05 \mathrm{~V} / \mathrm{s} ; \mathrm{CME}$ coating $1.13 \mathrm{mg} / \mathrm{cm}^{2} ; \mathrm{K}_{3} \mathrm{Fe}(\mathrm{CN})_{6}, 4 \mathrm{mM}$; Na-montmorillonite II.

concentration of clay, and $\theta$ is the immobilized water volume to clay volume.

\section{Results and Discussion}

Voltammetry. The transport of $\mathrm{Fe}(\mathrm{CN})_{6}^{3-}$ across the clay film was measured by its electrochemical reduction at the underlying platinum electrode when the potential is linearly swept over time between two potential limits $+0.6 \mathrm{~V}$ and $-0.2 \mathrm{~V}$ (SCE) in cyclic voltammetry, (Figure 1). It was shown that two types of diffusion, 9,10 linear and nonlinear, contribute to the voltammetric responses of $\mathrm{Fe}(\mathrm{CN})_{6}{ }^{3-}$ at the CME surface while a voltammetric response based on linear diffusion is usuall y observed with a rather large bare Pt electrode surface. To compare the solution diffusion $\left(D_{s}\right)$ and the effective or apparent diffusion in clay film $\left(D_{c}\right)$, experimental conditions were thus chosen where voltammetric responses are limited (1) by a linear diffusion process and (2) by a diffusion layer inside the clay film. This can be verified by varying the measurement sampling time (potential scan rate) and the deposited montmorillonite amount, i.e., the clay film thickness at the Pt electrode surface. The test is also performed in a $4 \mathrm{M} \mathrm{NaCl}$ bathing solution where the clay film thickness can be assumed to be thinnest i.e., under the lowest swelling conditions as discussed below. This allows the required experimental parameters used for the vol tammetric investigations to be defined more precisely. The transition between nonlinear and linear diffusion ${ }^{27}$ is characterized in cyclic voltammetry by thechange from a plateau-shaped voltammogram of constant current intensity to a peak-shaped vol tammogram whosecurrent intensity $\left(I_{p}\right)$ varies linearly with the square root of the potential scan rate, $v^{1 / 2}$. From the reported reduction current intensities plotted against $\mathrm{v}^{1 / 2}$ in Figure 2 , it can

(27) Amatore, C.; Saveant, J .-M.; Tessier, D. J . Electroanal. Chem. 1983, 147, 39. be shown that the transition occurs at lower potential scan rates or longer measurement time scales when the surfaceconcentration of montmorilloniteat the Pt surface increases. It must benoted that this peculiar vol tammetric behavior of $\mathrm{CME}$ in the bathing electrolyte $4 \mathrm{M} \mathrm{NaCl}$ can be found with microchannel array electrodes. ${ }^{28,29} \mathrm{~A}$ voltammetric response of CME based on a linear diffusion is thus found for potential scan rates, $v$, higher than 0.1 , 0.05 , and $0.02 \mathrm{~V} / \mathrm{s}$ at respective coated montmorillonite concentrations of $0.28,0.56$, and $1.13 \mathrm{mg} / \mathrm{cm}^{2}$. In the present work, a potential sweep rate of $0.05 \mathrm{~V} / \mathrm{s}$ and surface concentration of $1.13 \mathrm{mg} / \mathrm{cm}^{2}$ are the experimental parameters chosen to guarantee voltammetric detection based on a linear diffusion in the clay film.

Under these vol tammetric detection conditions, $I_{p}$ can thus be related to the concentration, $\mathrm{C}$, of $\mathrm{Fe}(\mathrm{CN})_{6}^{3-}$ in solution by the following general function

$$
\mathrm{I}_{\mathrm{p}}=\mathrm{K} \subset \mathrm{D}^{1 / 2} \mathrm{v}^{1 / 2}
$$

where $\mathrm{K}$ is a characteristic voltammetric constant which includes the Pt el ectrode surface, the number of el ectrons involved in the redox mechanism, and $\mathrm{D}$ is the diffusion coefficient of $\mathrm{Fe}(\mathrm{CN})_{6}{ }^{3-}$ in the solution $\left(\mathrm{D}_{\mathrm{s}}\right)$ or in the clay film $\left(D_{c}\right)$.

Theratio, $R$, of current intensity obtained at CME $\left(\mathrm{I}_{\mathrm{PCME}}\right)$ and bare Pt electrode $\left(I_{p_{s o}}\right)$ is used to measure the permeation properties of the clay films ${ }^{9}$

$$
R=\frac{I_{p_{C M E}}}{I_{p_{\text {sol }}}}
$$

(28) Tokuda, K.; Morita, K.; Shimizu, Y. Anal. Chem. 1989, 61, 1763. 1201 


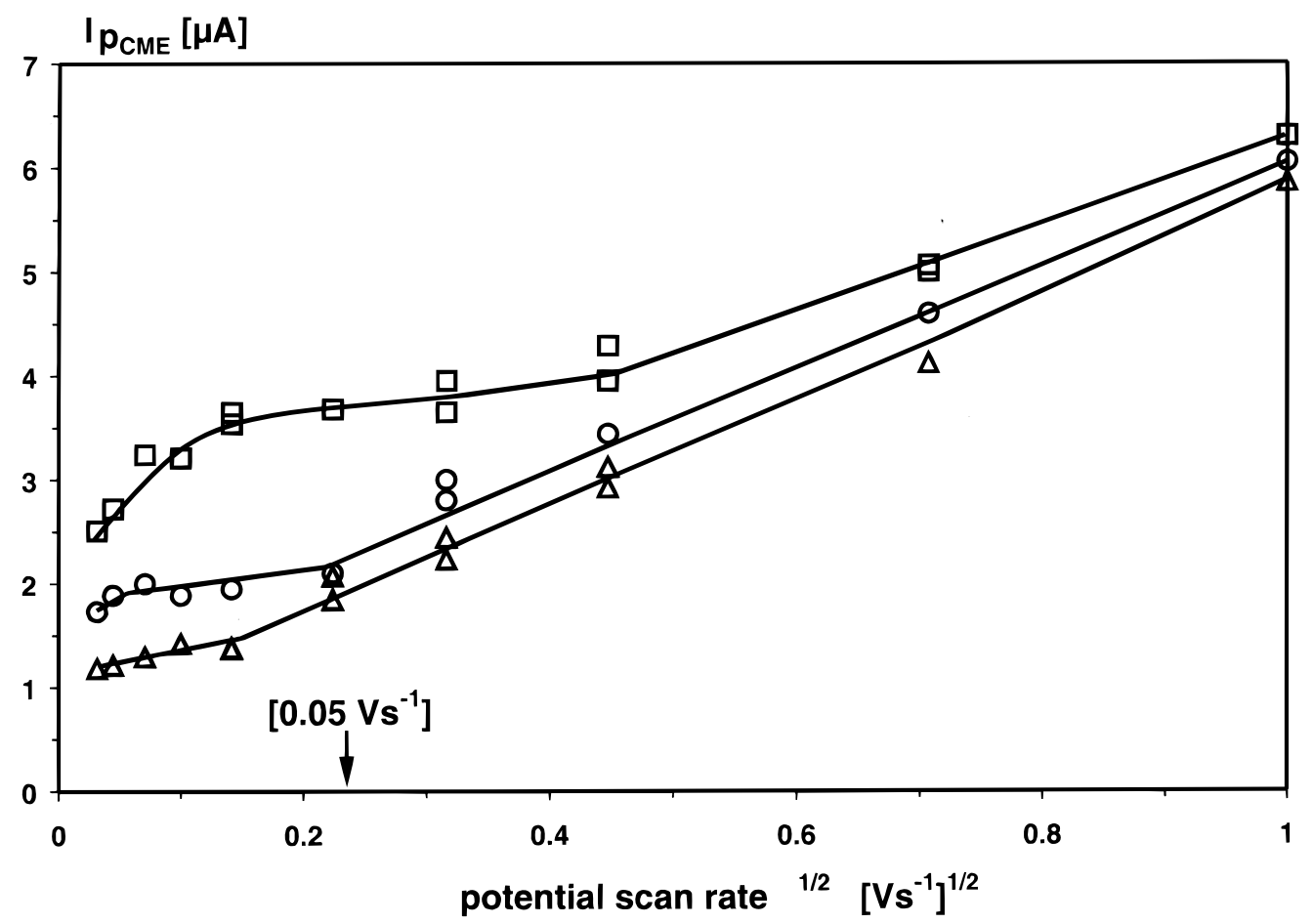

Figure 2. Effect of the potential scan rate on the reduction current intensity of $\mathrm{Fe}(\mathrm{CN})_{6}^{3-}$ for various $\mathrm{CME}$ coatings in $4 \mathrm{M} \mathrm{NaCl}$ solution. $\square$, CME coating $0.28 \mathrm{mg} / \mathrm{cm}^{2} ; \mathrm{O}, \mathrm{CME}$ coating $0.56 \mathrm{mg} / \mathrm{cm}^{2} ; \triangle, \mathrm{CME}$ coating $1.13 \mathrm{mg} / \mathrm{cm}^{2} ; \mathrm{K}{ }_{3} \mathrm{Fe}(\mathrm{CN})_{6}, 4 \mathrm{mM}$; Na-montmorillonitel.

In the case of of $\mathrm{Fe}(\mathrm{CN})_{6}^{3-}$, an unretained electroactive molecule in the clay film, it can be assumed that the solution concentration c inside and outside the clay film does not vary.

According to eqs 3 and 4 , the ratio of $D_{c}$ to $D_{s}$, which expresses the relative variation of $D$ in the clay film, is thus given by

$$
\mathrm{R}^{2}=\frac{\mathrm{D}_{\mathrm{c}}}{\mathrm{D}_{\mathrm{s}}}
$$

Salt Concentration Effect on the $\mathrm{Fe}(\mathrm{CN})_{6}{ }^{3-}$ Diffusion in CME. In most soils, anions which are not specifically adsorbed are in solution and are therefore mobile. ${ }^{30}$ Their diffusion through the poresolution is thus characterized by a diffusion coefficient close to those measured in the free solution, $D_{s}$. However, in a porous medium with decreasing moisture, an apparent variation of $D_{s}$ expressed in $D_{c}$ is measured which depends on the cross-sectional area available for diffusion. Thus, the decrease of theporosity, $\Phi$, and theincreaseof the diffusion path tortuosity are important retarding factors which limit the diffusion.

Clay Film Swelling. In the case of $\mathrm{Na}$-montmorillonite, a dependence between the deposited film swelling and the water activity was established. It was shown that in the presence of water dry montmorillonite swells in a stepwise fashion with the introduction of water layers between plates, ${ }^{22-24}$ al sotermed intracrystal lineswel ling. At a low water activity, a maximumstableplateseparation of 1.9-2 nm is reached for theN a-montmorillonite crystal, which is caused by the hydration of the exchangeable cations in theinterlayer. By increasing the water activity in the suspension, a sudden opening of the crystals occurs termed osmotic swelling where the basal spacing varies continuously. It results from the large concentration

(30) Nye, P. H. Adv. Agronomy 1979, 31, 225. difference between ions located at the clay mineral surfaces and in the water solution. Thus, in a $\mathrm{NaCl}$ concentration range from 0.01 to $0.3 \mathrm{M}$, low-angle $\mathrm{X}$-ray diffraction studies have shown that the average basal spacing $d_{001}$ linearly increases with $c_{s}^{0.5}$, where $c_{s}$ is the $\mathrm{NaCl}$ concentration in solution. 22

It follows that changing the water activity either by drying or by changing thesalt concentration would monitor the basal spacing of Na-montmorillonite. I $\mathrm{F}$ igure 3 , the $\mathrm{d}_{001}$ basal spacings and the voltammetric results ( $R(4)$ and $\mathrm{R}^{2}(5)$ ) arecompared in a $\mathrm{NaCl}$ solution concentration rangefrom 0.02 to $4 \mathrm{M}$. Themeasured (crystallineswelling) $\mathrm{d}_{001}$ basal spacings between 0.5 and $4 \mathrm{M} \mathrm{NaCl}$ arereported. The average $\mathrm{d}_{001}$ basal spacing results (osmotic swelling) from $\mathrm{N}$ orrish et al. ${ }^{22}$ in a $\mathrm{NaCl}$ solution concentration range from 0.02 to $0.2 \mathrm{M}$ are also included for comparison. A decrease of these parameters is observed as the salt concentration increases, which is related to a higher compactness of montmorillonite plates in the clay films by decreasing the water activity. Thus, a shrinking of the clay film decreases $\mathrm{Fe}(\mathrm{CN})_{6}{ }^{3-}$ transport to the electrode surface. It must be remarked that similar $\mathrm{R}$ value variations have been obtained under experimental conditions where a preswelling step in the bathing electrolyte solution is performed. ${ }^{9,12}$

It has been considered that thelong-rangebasal spacing of equilibrium between parallel-oriented single montmorillonite platel ets or face-faceinteractions can determine the structural aspect of a Na-montmorillonite homoge neous film. ${ }^{9}$ The void solution space between platelets corresponds to the film porosity which would control an intraparticle diffusion of the electrochemical marker. However, in the case of a trivalent anion such as $\mathrm{Fe}(\mathrm{CN})_{6}{ }^{3-}$, the electrostatic exclusion volume at the negatively charged surfaces of montmorillonite platelets, measured by twice the Debye length $(2 / \kappa),{ }^{31}$ as well as polarized 


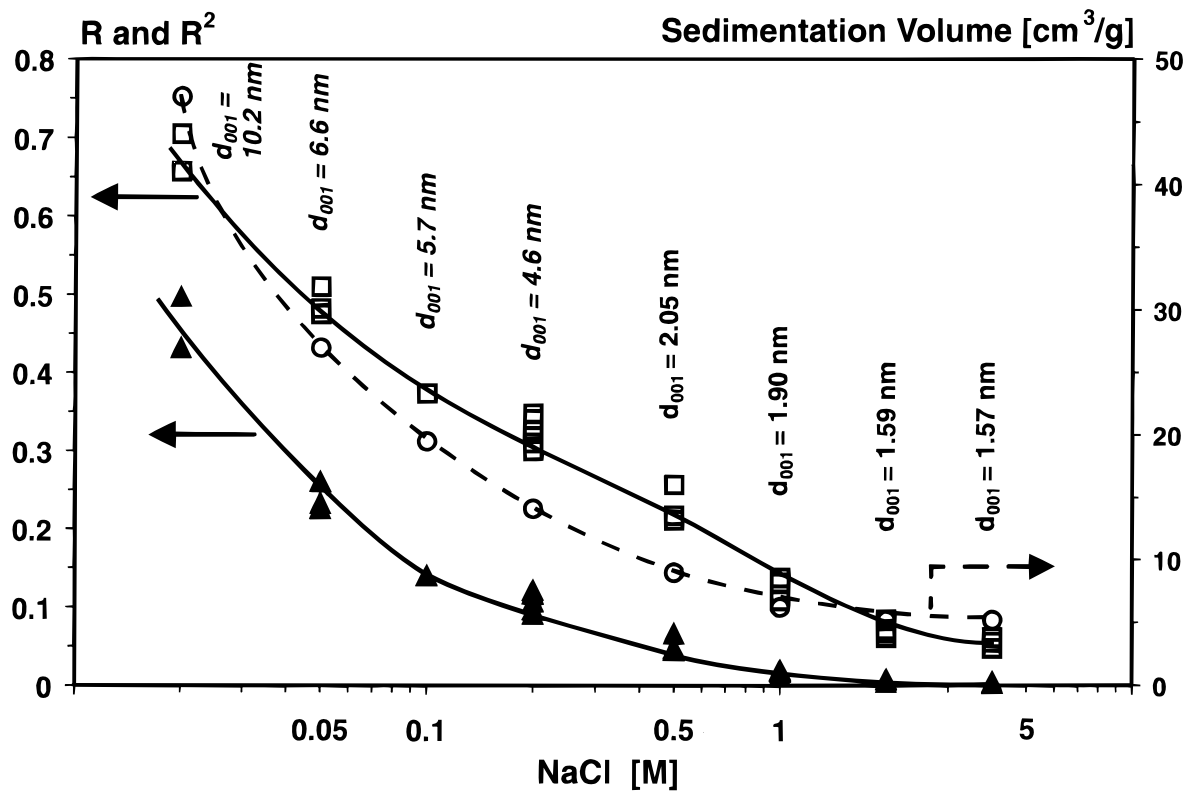

Figure 3. Effect of $\mathrm{NaCl}$ concentration on the montmorillonite clay sedimentation volume and cyclic voltammetric intensity current ratios $\mathrm{R}=\mathrm{I}_{\mathrm{P}_{\mathrm{CME}}} / \mathrm{I}_{\mathrm{p}_{\mathrm{SOl}}}$ and $\mathrm{R}^{2}$ (see $\mathrm{F}$ igure 1 ). $\mathrm{d}_{001}$ basal spacing values of $\mathrm{Na}$-montmorillonite are al so reported (see $\mathrm{M}$ ethods section and text). $\square, \mathrm{R} ; \boldsymbol{\Delta}, \mathrm{R}^{2}$; O, sedimentation volume; Na-montmorillonite I.

immobilized water layers of high viscosity (vicinal or surficial water), extending up to five monolayer thicknesses of water, 32 would occlude this pathway through the clay film. 30,33 An ideal Na-montmorillonite homogeneous film should thus be quasi-impermeable to the transport of $\mathrm{Fe}(\mathrm{CN})_{6}{ }^{3-}$ according totheseel ectrostatic and hydration properties of the montmorillonite surface.

However, microscopic, spectroscopic, and sorption studies ${ }^{34-38}$ givea more heterogeneous picture of the clay gel with an array of particles resulting from the heterogeneity of the surface density and the various bending potential of montmorilloniteparticles. Such arrangements could result in a discontinuous swelling of the CME film, in which interparticle pathways would control the permeability as discussed elsewhere.

Effective Porosity. To approach this CME film structure in contact with electrolyte solutions, the sedimentation vol umes $\left(\mathrm{V}_{\mathrm{sed}}\right)$ of concentrated montmorillonite solutions (10, 20, and $40 \mathrm{~g} / \mathrm{l} \mathrm{Na-montmorillonite)} \mathrm{were}$ measured. In Figure3, theaveragesedimentation volumes expressed in $\mathrm{cm}^{3}$ of water per $\mathrm{g}$ clay are reported against the $\mathrm{NaCl}$ solution concentration and compared to the vol tammetric results $\left(R, R^{2}\right)$.

In thesameway as for the $\mathrm{d}_{001}$ basal spacings, a decrease of $\mathrm{V}_{\text {sed }}$ is observed as the salt concentration in thesolution increases, i.e., as the water activity decreases. In particular, it can be shown, in Figure 4 , that a linear relationship exists $(r=0.99)$ between the sedimentation volumes and $R^{2}$ i.e., $D_{d} D_{s}$ which allows the following proposal to bemadefor approaching theclay film swelling effect on the $\mathrm{Fe}(\mathrm{CN})_{6}{ }^{3-}$ diffusion control.

(32) McBride, M. B.; Baveye, P. Soil Sci. Soc. Am. J . 1995, 59, 388. (33) Olsen, S. R.; Kemper, W. D.; Van Schalk, J . C. Soil Sci. Soc. Am. Proc. 1965, 29, 154.

(34) Fripiat, J.; Cases, J ;; François, M.; Lettelier, M. J . Colloid Interface Sci. 1982, 89, 378

(35) Van Damme, H.; Levitz, P.; Fripiat, J .J .;Alcover, J . F .; Gatineau, L.; Bergaya, F. In Physics of Finely Divided Matter; Boccara, N., Daoud, D., Eds.; Springer-Verlag: Berlin, 1985; p 24.

(36) Cases, J. M.; Bérend, I.; Besson, G.; Francois, M.; Uriot, J. P. Thomas, F.; Poirier, J . E. Langmuir 1992, 8, 2730.

(37) Morvan, M; Espinat, D.; Lambard, J.; Zemb, T. Colloids Surf. A 1994, 82, 193 .

(38) Murray, R. S.; Quirk, J . P. Soil Sci. Soc. Am. J . 1990, 54, 1179.
By anal ogy to the dipping of the air-dried CME surface in the electrolytesolution, the solid clay has been directly mixed with the electrolyte solution for the measurement of sedimentation volumes. The relative variation of the long-time stabilized (six months) Na-montmorillonite sedimentation volumes is used to calculate an effective solution-filled porosity, $\Phi_{e}$, of the clay film for $\mathrm{Fe}(\mathrm{CN})_{6}{ }^{3-}$. In this cal culation, theextrapolated sedimentation volume $\mathrm{V}_{\text {sed }}{ }^{\mathrm{R}^{2}=0}$ at $\mathrm{R}^{2}=0$ would characterize an occluded compactness structure of the clay film which was taken as a reference state in the following relation

$$
\Phi_{\mathrm{e}}=\frac{\mathrm{V}_{\text {sed }}-\mathrm{V}_{\text {sed }}^{\mathrm{R}^{2}=0}}{\mathrm{~V}_{\text {sed }}}
$$

It must be noted that $\mathrm{V}_{\text {sed }}$ given by thelinear regression analysis when $\mathrm{R}^{2} \rightarrow 0$ matches the $\mathrm{V}_{\text {sed }}$ results obtained at salt concentrations higher than $1 \mathrm{M} \mathrm{NaCl}$. Thus, the $\mathrm{V}_{\text {sed }}$ result obtained in $4 \mathrm{M} \mathrm{NaCl}$ was used for the calculation of $\Phi_{\mathrm{e}}$ with eq 6 .

In the following discussion, the $D_{d} D_{s}$ and $\Phi_{e}$ results obtained at $\mathrm{c}_{\mathrm{s}} \leq 1 \mathrm{M} \mathrm{NaCl}$ are thus considered. In Figure 5 , the variation of the relative diffusion coefficient of $\mathrm{Fe}(\mathrm{CN})_{6}{ }^{3-}$ is reported against the so-derived efficient porosity $\Phi_{\mathrm{e}}$. As expected, a large decrease of $D_{d} D_{s}$ is observed as the calculated efficient porosity, $\Phi_{e}$, nears zero, which has been further modeled.

Modeling. In thecase of the conductancemeasurements of electrolyte solution-filled porous montmorillonite gels, a general way to understand the tortuosity effects on the ion diffusion is to consider the formation factor, ${ }^{30} \mathrm{~F}$. This measures the extent to which the solid particles reduce the specific conductance of the montmoril lonite gels $\left(\mathrm{k}_{\mathrm{gel}}\right)$ in relation to the solution $\left(k_{s}\right), F=k_{s} / k_{\text {gel }}$.

E mpirical relations between porosity $(\Phi)$ and formation factor $(F)$ including a tortuosity effect $(\tau)$ are generally established ${ }^{11,30}$

$$
\text { F function }(\Phi, \tau)
$$

In the case of montmorillonite gels, it was found that 


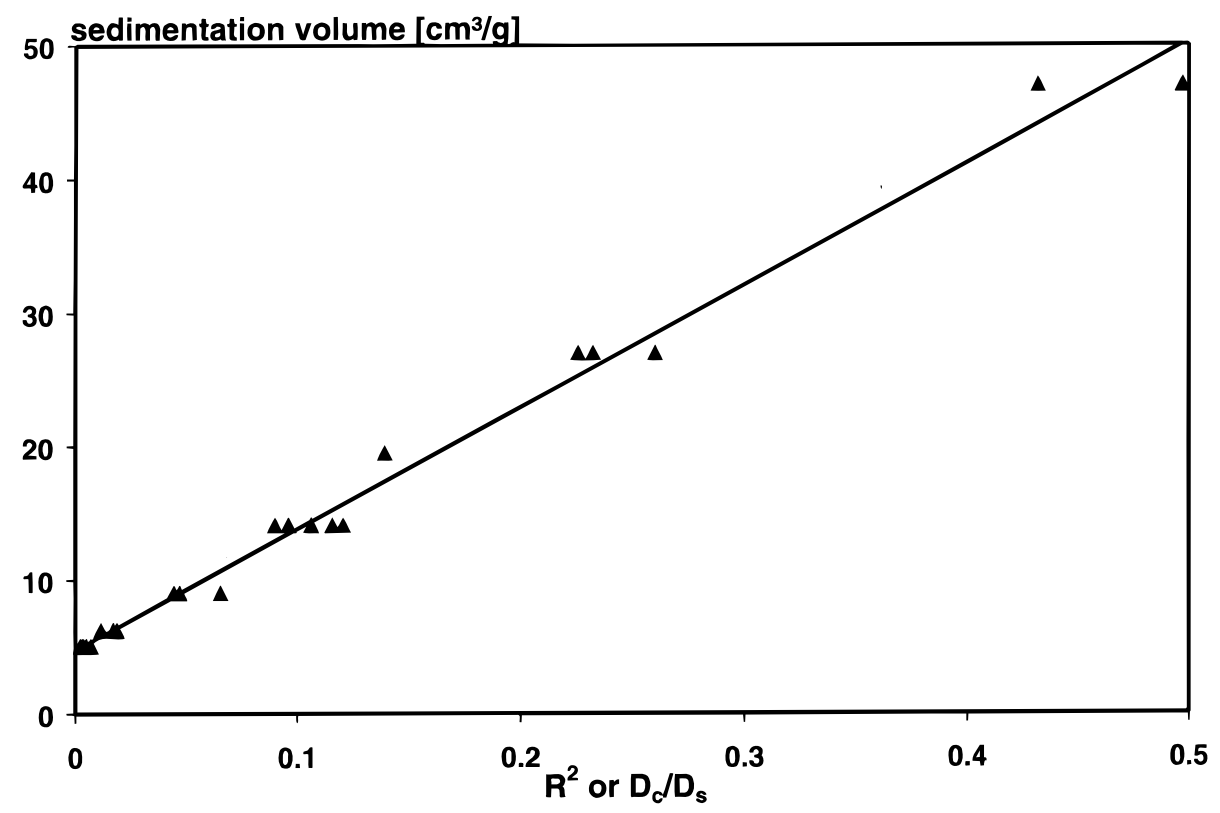

Figure 4. Relationship between the sedimentation volumes and therel ative variation of the Fe $(\mathrm{CN})_{6}{ }^{3-}$ diffusion coefficient at $\mathrm{CM} \mathrm{E}$ expressed in $R^{2}=D_{d} / D_{s}$, (see also Figure 3).

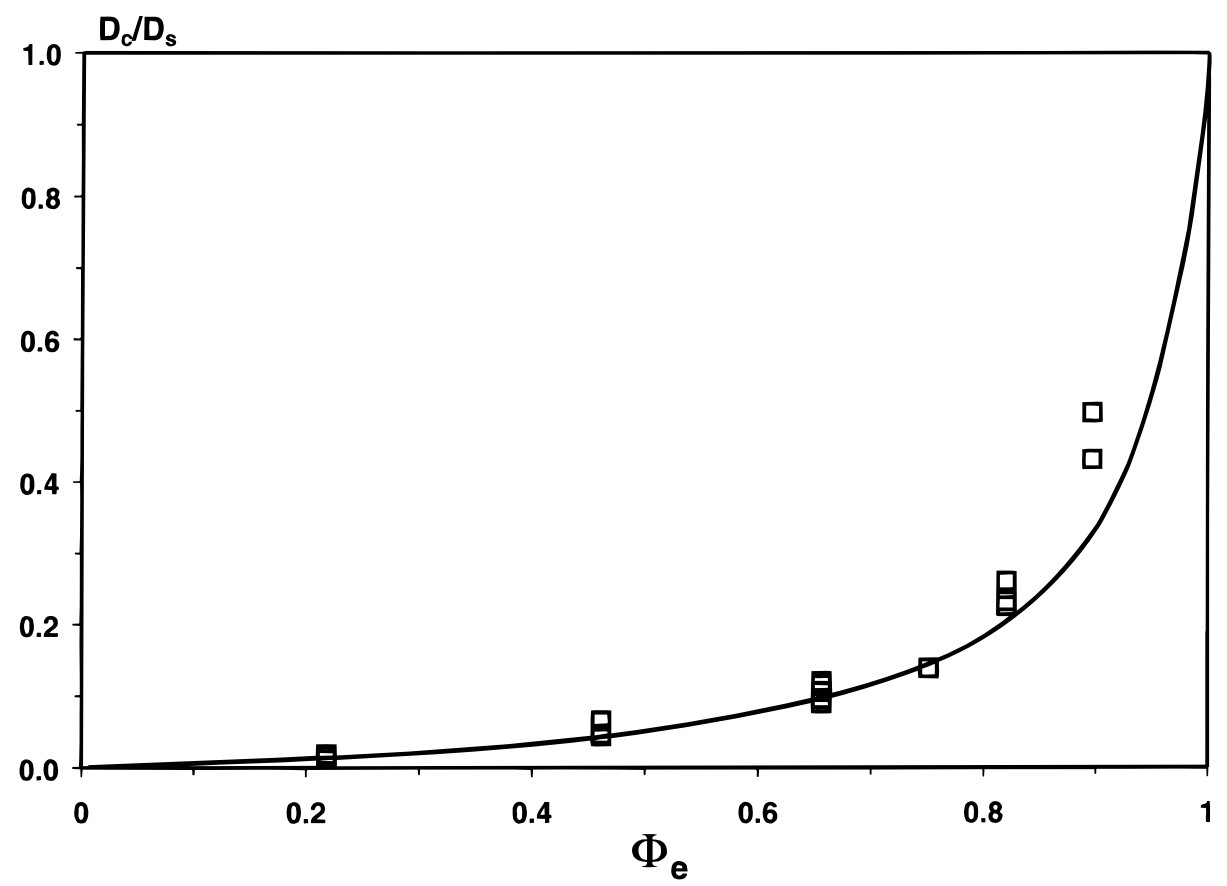

Figure 5. Dependence of the relative variation of $\mathrm{Fe}(\mathrm{CN})_{6}{ }^{3-}$ diffusion coefficient at $C M E, R^{2}=D_{d} / D_{s}$ on the effective porosity $\Phi_{e}$ (calculated with eq 6). The curve is calculated with eq 7 where the shape factor $\alpha=17.8$ (see also text).

F is well described by a theoretical equation after Fricke 39 for the electric conductivity of solutions containing homogeneous spheroids

$$
\mathrm{F}=1+\alpha \frac{(1-\Phi)}{\Phi}
$$

where $\alpha$, theshapefactor, depends on particles geometrical factors that account for thetortuosity effects. By assimiling montmorillonite particles to oblate spheroids (ellipsoid of revolution about minor axis $B$ ), satisfactory results have

(39) Fricke, H. Phys. Rev. 1924, 24, 575. been obtained in establishing a relati onship between the clay gel porosity, particle axial ratio, and the formation factor. ${ }^{40-42}$

In this work, a diffusion model based on the same theoretical approach was considered where $F$ is set equal to $D_{s} / D_{c}$ according to the Nernst-E instein relation connecting the diffusion transport process and conductance. ${ }^{43}$

Knowing $D_{d} / D_{s}$ from voltammetric measurements (eq 5), it follows that

(40) Cremers, A.; Laudelout, H. J . Chim. Phys. 1965, 62, 1155.

(41) Dufey, J . E.; Laudel out, H. G. J . Colloid InterfaceSci. 1975, 51 278.

(42) Dufey, J . E.; Banin, A.; Laudel out, H. G.; Chen, Y. Soil Sci. Soc. Am. J . 1976, 40, 310.

(43) Kariuki, S.; Dewald, H. D. Electroanalysis 1996, 8, 307. 


$$
\mathrm{F}=\frac{1}{\mathrm{R}^{2}}=\frac{\mathrm{D}_{\mathrm{s}}}{\mathrm{D}_{\mathrm{c}}}=1+\alpha \frac{\left(1-\Phi_{\mathrm{e}}\right)}{\Phi_{\mathrm{e}}}
$$

where $\alpha$ only depends on the shape and orientation of the particles.

In the case of a random orientation of the oblate spheroids, ${ }^{39}$ the shape factor $\alpha$ can be related to the axial ratio $A / B$ of the particle with

$$
\alpha=\frac{1}{3}\left(\frac{2}{1-\frac{1}{2} M}+\frac{1}{M}\right)
$$

where

$$
M=\frac{\left(\rho-\frac{1}{2} \sin 2 \rho\right)}{\sin ^{3} \rho} \cos \rho
$$

and

$$
\cos \rho=\frac{\mathrm{B}}{\mathrm{A}}
$$

with $\mathrm{A}=$ diameter of the particle and $\mathrm{B}=$ thickness of the particle.

For $A / B$ values $>5$ in eqs 10,11 , and 12 , a linear relationship exists between $\alpha$ and $A / B$.

$$
\alpha=0.982+0.212 \frac{A}{B} \quad\left(r^{2}=1\right)
$$

It must be remarked that eq 10 obtained for oblate spheroids is a special case of a more general expression for an ellipsoid geometry which is defined along three axes $a, b$, and $c$. F or the more simple geometry of oblate spheroid where $a=b=n c(n$ or $A / B>1)$; eq 10 giving the shape factor $\alpha$ can be discriminated into the following relations along the particle axis $a$ and $b$ (major axis $A$ ) and $\mathrm{C}$ (minor axis B).

For the case where the A axis is parallel to the $\mathrm{Fe}(\mathrm{CN})_{6}{ }^{3-}$ anion concentration gradient or perpendicular to the electrode surface, the shape factor $\alpha$ can be thus defined

$$
\alpha=\frac{1}{1-\frac{1}{2} M}
$$

For $A / B$ values $>1$, it can be shown with eqs 11 and 12 that

$$
\alpha \rightarrow 1 \text { for } A / B>1
$$

For thecasewherethe $\mathrm{B}$ axis is parallel tothe $\mathrm{Fe}(\mathrm{CN})_{6}{ }^{3-}$ anion concentration gradient or perpendicular to the electrode surface, it can be found that

$$
\alpha=\frac{1}{M}
$$

For $A / B$ values $>1$, it can be calculated with eqs 11,12 , and 16 that

$$
\alpha=0.806+0.637 \frac{\mathrm{A}}{\mathrm{B}} \quad\left(r^{2}=1\right)
$$

Equations 13, 15, and 17 between the shape factor $\alpha$ and the axial ratio $A / B$ are reported in Figure 6.

In Figure 7, F - 1 results, as defined in eq 9, are plotted against $\left(1-\Phi_{\mathrm{e}}\right) / \Phi_{\mathrm{e}}$. From the slope of thelinear relation- ship, an averagevalue $\alpha=17.8 \pm 1\left(r^{2}=0.95\right)$ is cal culated. In Figure 5, it can be shown that a constant shape factor describes the reported experimental results fai rly well in the range of the calculated clay film effective porosities $\Phi_{\mathrm{e}}$ from 0.2 to 0.8 , i.e., under conditions of bathing electrolyte concentrations higher than $0.05 \mathrm{M} \mathrm{NaCl}$.

According to eqs 13 and 17 , the calculated shape factor $\alpha \gg 1$ also supposes that a large fraction of the particles are oriented to the electrode surface with the major axis A or the particle diameter lying paral lel to the electrode surface (horizontal deposition). An estimation of the particles' $A / B$ axial ratios in the clay film give values of $79 \pm 5$ and $27 \pm 2$, respectively for random and horizontal depositions. For comparison, the A/B axial ratio of highly disper sed $\mathrm{Na}$-montmorillonite particles in water has been calculated from specific viscosities $\left(\eta_{\mathrm{sp}}\right)$ measurement. $\eta_{\mathrm{sp}}$ values of $0.019,0.026$, and 0.038 have been measured with $0.50,0.67$, and $1 \mathrm{~g} / \mathrm{l} \mathrm{Na-montmorillonite} \mathrm{solutions,}$ respectively. An A/B axial ratio of 130 can bethus obtained with $[\eta]=110$ and $\theta=0$ in eqs 1 and 2 .

It is obvious from the modeling in Figure 6 that a horizontal deposition (III) at the electrode surface of montmorillonite particles with a low axial ratio also hinders $\mathrm{Fe}(\mathrm{CN})_{6}{ }^{3-}$ transport, as in the case of randomly deposited particles (I) with a higher axial ratio.

In the case of spin-coating onto a small platinum electrode, a well-ordered clay film or gel can be formed wherea horizontal deposition of montmorilloniteparticles prevails. ${ }^{5,9}$ The rather constant $\alpha$ val ue found at bathing electrolyte concentrations higher than $0.05 \mathrm{M} \mathrm{NaCl}\left(\Phi_{\mathrm{e}}\right.$ $<0.8$ ) supposes the presence of montmorillonite particles with a constant shape and orientation which will be discussed.

Thus, spectroscopic investigations of swelling smectite gels have established the existence of stable face-to-face aggregates (tactoids) ${ }^{34-37}$ with a fairly constant size. They sustain the gel network which delimits swelling lenticular pores. ${ }^{45}$ In solution, at electrolyte concentrations higher than $0.05 \mathrm{M} \mathrm{NaCl}$, this cl ose stacking of montmorill onite plates along the B axis (thickness) is also favored. A maxi mal stable basal spacing of about $2 \mathrm{~nm}$ characterizes the quasicrystalline nature of the tactoidal intraparticle structure (seecrystalline swelling of $\mathrm{Na}$-montmorillonite in Figure 3 and text). At low electrolyte concentrations, the osmotic swelling ensures a maximum plate separation giving rise to high basal spacing. However, the presence of stabletactoids is al so widely documented ${ }^{26,44}$ wherethe number of clay plates in the tactoids generally increases with theatomic weight and thecharge of theexchangeable cation.

The formation of nonpermeable montmorillonite particles with a low axial ratio A/B can be also envisaged in the dense clay film structure of CME. The permeability of the clay film would thus depend on interparticle nonoccluded swelling pathways limited by domains with close-packed montmorillonite platelets, where an intraparticle or interlayer diffusive transport of $\mathrm{Fe}(\mathrm{CN})_{6}{ }^{3-}$ is excluded. ${ }^{12}$ The fact that $\mathrm{Fe}(\mathrm{CN})_{6}{ }^{3-}$ diffuses through the clay film al so indicates that the swell ing volume is larger than the anion-exclusion and hydratation volumes extending at themontmorillonitesurface. Thiscan berelated to the stiffness of the tactoidal structure which restricts a proper parallel alignment of the particles as would be

(44) Schramm, L. L.; Kwak, J . C. T. Clays Clay Miner. 1982, 30, 40. 76 


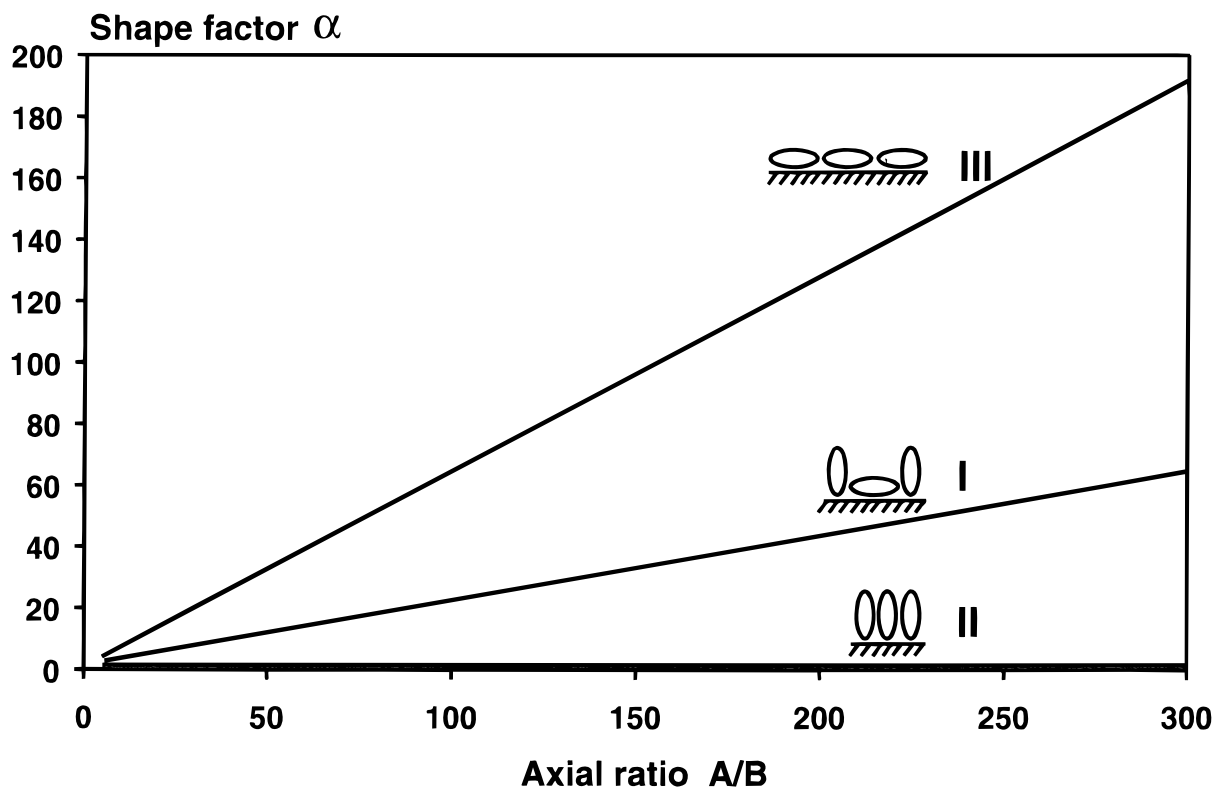

Figure 6. Effect of the particle orientation in a deposited film on the theoretical dependence between the shape factor $\alpha$ and the particle axial ratio $A / B$ of the oblate spheroid $(A \gg B)$. I: random orientation, eq 13; II: perpendicular orientation of $A$ axis, eq 15; III: parallel orientation of A axis, eq 17.

\section{F-1}

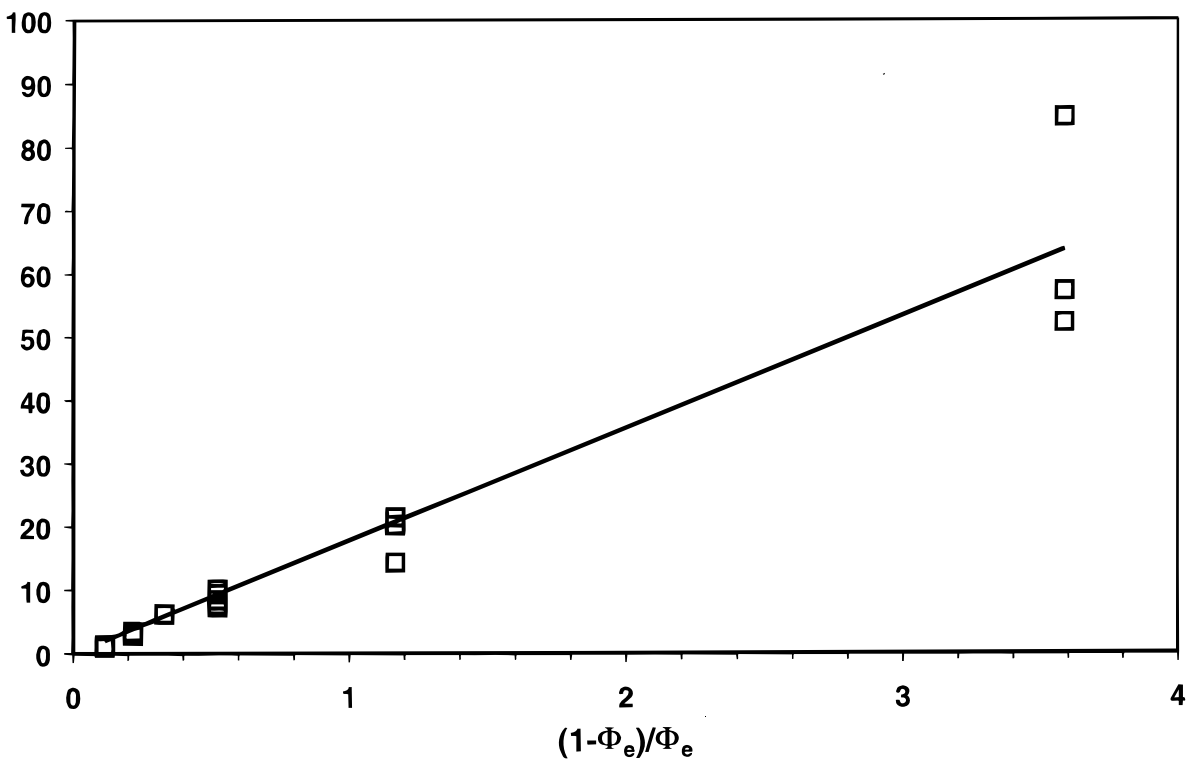

Figure 7. Linear regression analysis of the relation between the formation factor $F$ and the effective porosity $\Phi_{\mathrm{e}}$ according to eq 7.

found with highly flexible single montmorillonite platelets. ${ }^{46}$ It results in a larger porosity.

At an effective porosity $\Phi_{e}>0.8$, in Figure 5 , higher $D_{d} D_{s}$ values than the simulated results are observed. Low $\alpha$ values can be calculated which indicate a more random orientation of the montmorillonite particles (Figure6) probably duetothree-dimensional edge-to-face interactions which prevail at $\mathrm{NaCl}$ concentrations lower than $0.05 \mathrm{M} \mathrm{NaCl} .{ }^{45}$ The presence of a foreign exchangeable cation such as $\mathrm{K}^{+}$from the $4 \mathrm{mM} \mathrm{K}{ }_{3} \mathrm{Fe}(\mathrm{CN})_{6}$ solution during the clay swelling process could also increase the diffusion ${ }^{47}$ through additional dislocation of thefilm under the conditions of low $\mathrm{NaCl}$ bathing concentrations.

(46) Van Damme, H.; Ben Ohoud, M. In Disorder and Fracture; Charmet, J. C., Roux, S., Eds.; Plenum Press: New York, 1990; p 105.

(47) Fitch, A.; Du, J .; Gan, H.; Stucki, J . W. Clays Clay Miner. 1995, 43, 607.
In the same way, the measured $\mathrm{R}^{2}$ values much smaller than $1 \%$ at $4 \mathrm{M} \mathrm{NaCl}$ (Figure 3) can be due to tactoid rearrangement during theweting and drying cycle of $\mathrm{CME}$ preparation. It results in intrinsic failures ${ }^{38}$ which are detected by typical cyclic voltammetric responses for a microchannel electrode (Figure 2).

Effects of Water-Soluble Polymers. The strong interactions of polymers with clay minerals are due to multisite adsorption through the monomer units at the surface. I t results in various modifications of clay mineral surface properties which mainly depend on the nature of themonomer functional groups and the polymer molecular weights. Polymers affect the aggregate stability of clay mineral and can thus modify the hydraulic conductivity of coating layered clay minerals structures. This has been investigated by measuring theF $\mathrm{e}(\mathrm{CN})_{6}{ }^{3-}$ diffusion at $\mathrm{CME}$ previously modified by water-solubl esynthetic polymers 

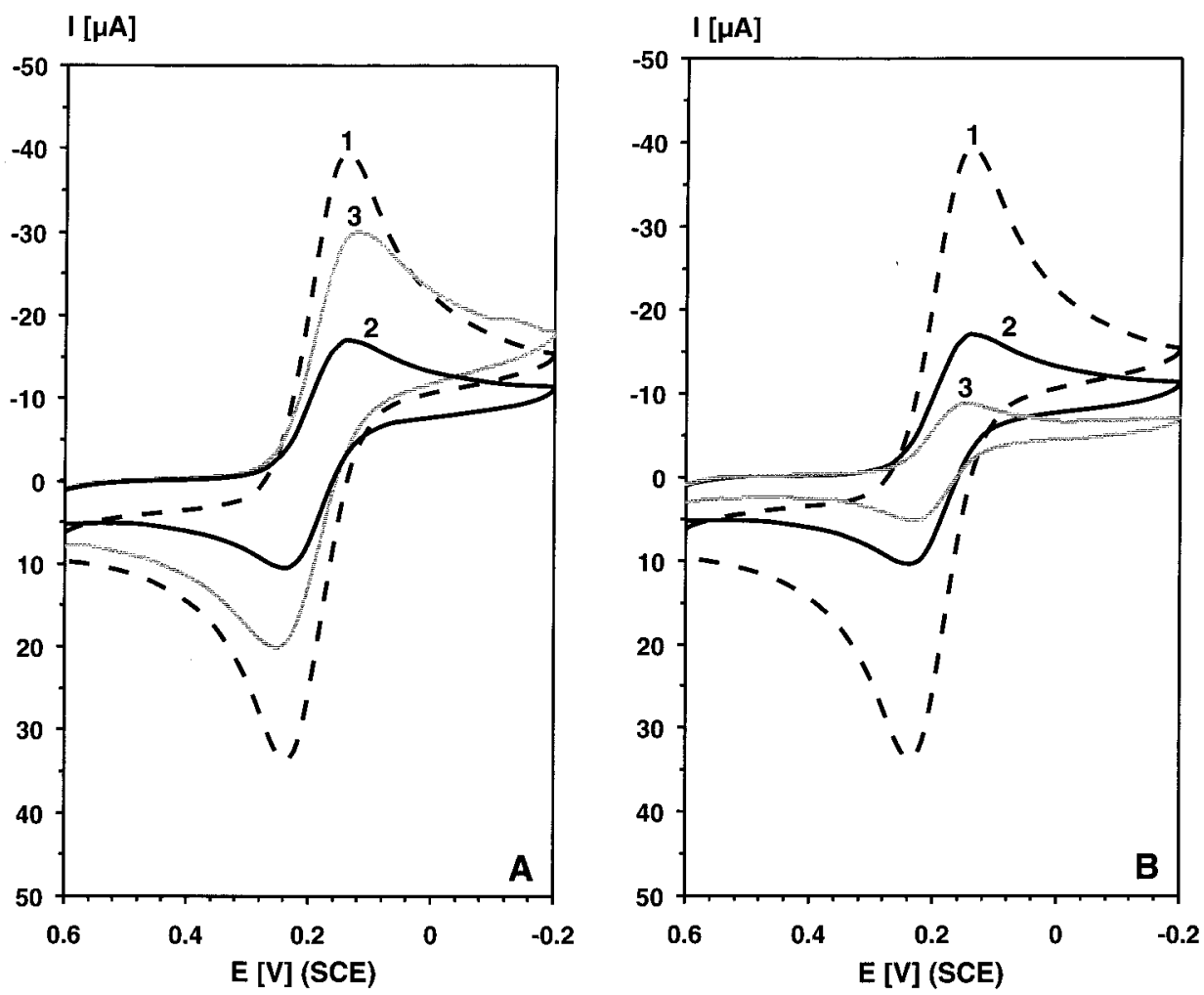

Figure 8. Cyclic vol tammetric responses of $\mathrm{Fe}(\mathrm{CN})_{6}{ }^{3-}$ at polymer-modified $\mathrm{CME}$ (w/w: $5 \%$ ) in $0.2 \mathrm{M} \mathrm{NaCl}$ solution. A: 1 , bare-Pt electrode; 2, unmodified CME; 3, PAA (MW 2000 g/mol)-modified CME. B: 1, bare Pt electrode; 2, unmodified CME; 3, PVP (MW $44000 \mathrm{~g} / \mathrm{mol}$ )-modified CME. Potential scan rate $0.05 \mathrm{~V} / \mathrm{s} ; \mathrm{CME}$ coating $1.13 \mathrm{mg} / \mathrm{cm}^{2} ; \mathrm{K}_{3} \mathrm{Fe}(\mathrm{CN})_{6}, 4 \mathrm{mM} ; \mathrm{Na}$-montmorillonite II.

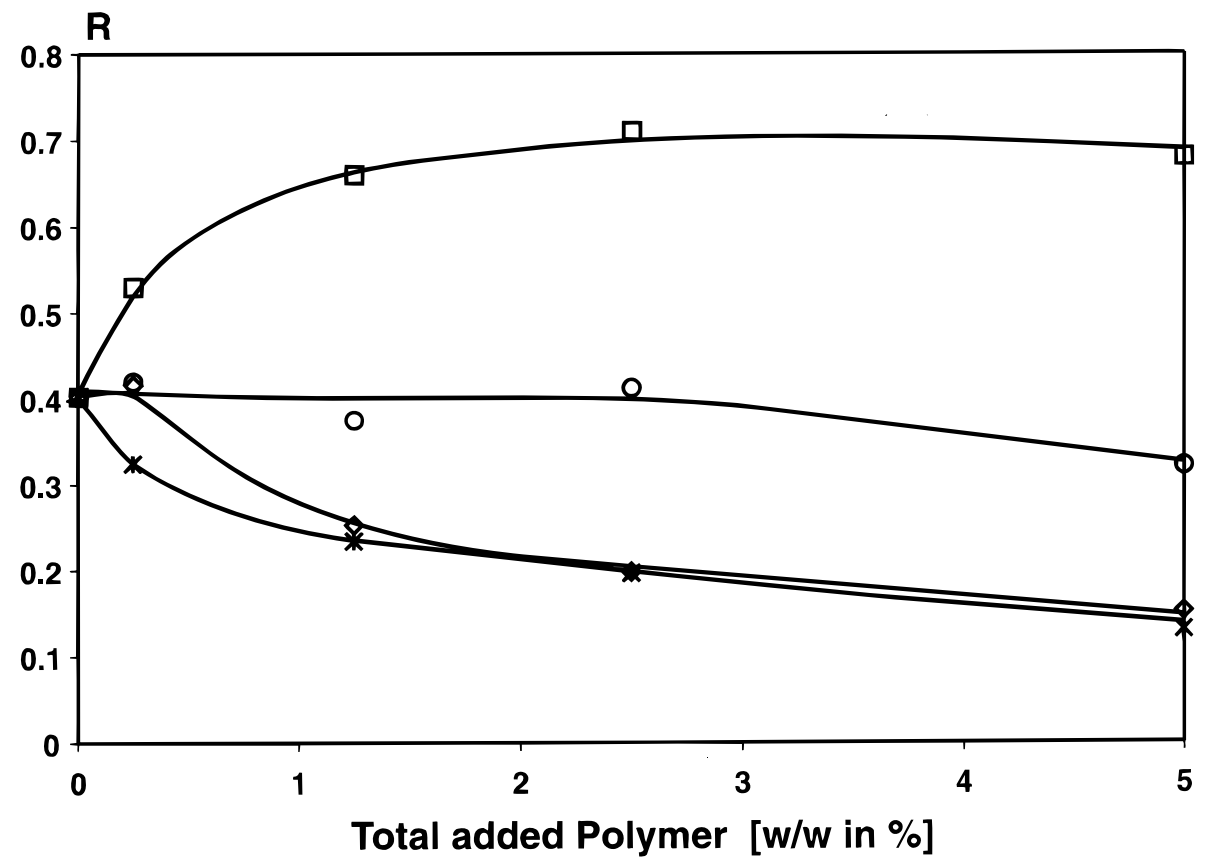

Figure 9. Effects of the water-soluble polymer content (w/w) of CME on the cyclic voltammetric intensity current ratios $\mathrm{R}=$ $\mathrm{I}_{\mathrm{P}_{C M E}} / \mathrm{I}_{\mathrm{p}_{\text {sol }}}$ of $\mathrm{Fe}(\mathrm{CN})_{6}{ }^{3-}$ in $0.2 \mathrm{M} \mathrm{NaCl}$ solution. O, PVP (MW $5000 \mathrm{~g} / \mathrm{mol}$ ); $*, \mathrm{PVP}(\mathrm{MW} 44000 \mathrm{~g} / \mathrm{mol}$ ); $\diamond, \mathrm{PVP}$ (MW $400000 \mathrm{~g} / \mathrm{mol}$ ); 口, PAA (MW $2000 \mathrm{~g} / \mathrm{mol}$ ); Na-montmorillonite II.

of varying chemical compositions and molecular weights. In this study, polymers of a polyanionic character such as poly(acrylic acid) (PAA) as well as the nonionic polymer, poly(vinylpyrrolidone) (PVP), were considered.

Cyclic Voltammetric Results. Figure8showstypical cyclic voltammetricresponses of $\mathrm{Fe}(\mathrm{CN})_{6}{ }^{3-}$ obtained with unmodified and polymer-modified CME in $0.2 \mathrm{M} \mathrm{NaCl}$ solution. It can be seen that a $5 \%(\mathrm{w} / \mathrm{w})$ polymer modification of CME with PAA (MW $2000 \mathrm{~g} / \mathrm{mol}$ ) sensitively increases the intensity current (Figure 8, A) while the same percentage of modification with PVP (MW 44000 $\mathrm{g} / \mathrm{mol}$ ) greatly decreases thecycl icvoltammetric response (Figure 8B).

In Figure 9, the dependence of R (4) on the weight percentage of up to $5 \%(\mathrm{w} / \mathrm{w})$ of added polymers in the Na-montmorillonite solution used for CME preparation is plotted. In a $0.2 \mathrm{M} \mathrm{NaCl}$ solution, the voltammetric results show an increase of $\mathrm{R}$ in the case of a CME 
Table 1. Effects of Water-Soluble Polymers; Experimental Results and Modeling Parameters

\begin{tabular}{|c|c|c|c|c|c|c|c|c|}
\hline \multirow{2}{*}{$\begin{array}{c}\text { water-soluble } \\
\text { polymer (w/w: } 5 \%)\end{array}$} & \multicolumn{2}{|c|}{ sedimentation volume $\left[\mathrm{cm}^{3} / \mathrm{g}\right]$} & \multirow[b]{2}{*}{$\Phi_{\mathrm{e}}$} & \multirow[b]{2}{*}{$\mathrm{R}$} & \multirow[b]{2}{*}{$\mathrm{F}=\mathrm{D}_{\mathrm{s}} / \mathrm{D}_{\mathrm{c}}$} & \multirow[b]{2}{*}{$\alpha$} & \multicolumn{2}{|c|}{$\overline{\mathrm{d}}_{\mathrm{z}}[\mu \mathrm{m}](\mathrm{PCS})$} \\
\hline & $0.2 \mathrm{M} \mathrm{NaCl}$ & $4 \mathrm{M} \mathrm{NaCl}$ & & & & & water & $0.2 \mathrm{M} \mathrm{NaCl}$ \\
\hline without polymer & 31 & 5.5 & 0.82 & 0.400 & 6.2 & 24 & 0.45 & 3 \\
\hline PAA (MW $2000 \mathrm{~g} / \mathrm{mol}$ ) & 24 & 4 & 0.83 & 0.680 & 2.2 & 6 & 0.45 & 0.65 \\
\hline PVP (MW $5000 \mathrm{~g} / \mathrm{mol}$ ) & 31.5 & 4.5 & 0.86 & 0.320 & 9.8 & 50 & 0.45 & 3 \\
\hline PVP (MW $44000 \mathrm{~g} / \mathrm{mol}$ ) & 18.8 & 4.5 & 0.76 & 0.135 & 55.5 & 173 & 0.75 & 4 \\
\hline PVP (MW $400000 \mathrm{~g} / \mathrm{mol}$ ) & 15 & 4 & 0.73 & 0.145 & 47.6 & 126 & 0.55 & 4 \\
\hline
\end{tabular}

modification with a low-molecular-weight PAA (MW 2000 $\mathrm{g} / \mathrm{mol}$ ) polymer partially ionized at $\mathrm{pH}$ 5.6, whilea decrease of $\mathrm{R}$ is observed for CME modification with different PVP molecular weights of 5000, 440000 , and $400000 \mathrm{~g} / \mathrm{mol}$. In the case of PVP, the voltammetric results also show a dependence of the polymer molecular weights used for CME modification. Thus, thepresence of $1 \%$ PVP polymers of MW $44000 \mathrm{~g} / \mathrm{mol}$ or MW $400000 \mathrm{~g} / \mathrm{mol}$ in the CME more effectively decreases the relative current intensity $\mathrm{R}$ than a $5 \%$ addition of the PVP polymer with the lowest MW $5000 \mathrm{~g} / \mathrm{mol}$.

It must be noted that peak-shaped cyclic voltammetric responses of $\mathrm{Fe}(\mathrm{CN})_{6}{ }^{3-}$, in $\mathrm{F}$ igure 8 , are al ways obtained with unmodified and polymer-modified CME in $0.2 \mathrm{M} \mathrm{NaCl}$ solution. They are proportional to the square root of the potential scan rate and are typical of a linear diffusion inside the clay film. Theapplication of eq 3 for measuring a relative diffusion of $\mathrm{Fe}(\mathrm{CN})_{6}{ }^{3-}, \mathrm{D}_{d} \mathrm{D}_{\mathrm{s}}$, is thus applied and the variations of the formation factor $F$ were used to characterizethe polymer impact on theclay filmstructure.

Polymer Adsorption Behavior. Beforediscussing possible arrangements of the clay domains in the coated montmorillonitelayer, some information about the adsorption characteristics of the polymers must be briefly reviewed. Under thesolution concentration conditions used for CME preparation, it can be considered that the polymer adsorption at the montmorillonite surface is quasitotal. ${ }^{48-50,52}$ I $n$ the case of PAA, it has been shown that the adsorption of negatively ionized polycarboxylic polymer is el ectrostatically hindered at the permanent negatively charged siloxane plate surface. However specific binding of polycarboxylate at aluminol sites of the edge surface can take place through a ligand exchange mechanism.

In the case of the nonionic PVP polymer, an overall adsorption at montmorillonite surfaces occurs. The building of the fl occulated polymer/montmorillonite structure is possi ble where PVP polymers are layered between the siloxane plates. ${ }^{51}$

Modeling Parameters. Taking into account these polymer adsorption characteristics, the modifications of the clay film permeability are now discussed with the help of the modeling results.

Voltammetricand sedimentation volumes results were moreover considered for the case of a $5 \%$ addition of polymers (PAA and PVP) in the deposited clay film at the platinum el ectrode. The sedimentation vol umes obtained under $4 \mathrm{M} \mathrm{NaCl}$ salt solution conditions were also taken as a reference state for the calculation of an effective porosity $\Phi_{\mathrm{e}}$ with eq 6 .

In Table 1 , sedimentation volumes, $\Phi_{e}, R, F$ or $D_{s} / D_{c}$, and $\alpha$ calculated with eq 9 are reported for comparison. A rapid overview shows that no correlation can be found

(48) Blockhaus, F.; Séquaris, J.-M.; Narres, H. D.; Schwuger, M. J . I. Colloid Interface Sci. 1997, 186, 234.

(49) Hild, A.; Séquaris, J .-M.; Narres, H. D.; Schwuger, M. J . Colloids Surf. A 1997, 123-124, 515.

(50) Bassmann, F.; Séquaris, J .-M.; Narres, H. D.; Schwuger, M. J . J. Dispersion Technol. 1999, 20(1\&2), 607.

(51) Francis, C. W. Soil Sci. 1973, 115, 40

(52) Séquaris, J .-M.; Bassmann, F.; Hild, A.; Narres, H. D.; Schwuger, M. J . Colloids Surf. A 1999, 159 (2\&3), 503-512. between the shape factor $\alpha$ and the effective porosity $\Phi_{e}$ after the different polymer modifications of theCME. Thus, in a small range of effective porosities, $\Phi_{e}=0.80 \pm 0.06$, calculated $\alpha$ values vary from 6 to 173 . According to the results expressed in eqs 13 and 17 in Figure 6, such a dispersion of the shape factor values can be modeled by various orientations and axial ratios of montmorillonite particles in the clay film.

In the case of the PAA modification, for a constant A/B axial ratio value, the decrease of $\alpha$ would indicate a more vertical deposition of the CME film. On the other hand, in the case of a fixed particle orientation in the clay film, the reduction of $\alpha$ could be related to a decrease of the axial ratio $A / B$ values.

A contrasting behavior for the arrangement of the clay particles in the CME film can be now assumed after PVP modification. The increase of $\alpha$ would indicate either a more horizontal deposition of the clay film if the axial ratio remains constant or an increase of the axial ratio $A / B$ in the case of an unmodified orientation of particles.

These interpretations are restricted to a single parameter variation. It is clear that simultaneous variations of the two $\alpha$-determining parameters, particle orientation and axial ratio, can also be considered. Therefore, an attempt was made to specify some major parameter variations from other experimental results.

Sedimentation Volume and Photon Correlation SpectroscopicR esults. I n the presence of polymers, the decrease of thesedimentation volumes of montmorilloniteparticles supposes a collapse of the montmorillonite gel network. However, measurements (Table 1) with photon correlation spectroscopy (PCS) of the polymer-modified montmorilIonite particles in $0.2 \mathrm{M} \mathrm{NaCl}$ show marked differences in their hydrodynamic behaviors. Thus, an average hydrodynamic diameter value, $\overline{\mathrm{d}}_{\mathrm{z}}$, of about $3 \mu \mathrm{m}$ can be cal culated for unmodified montmorillonite particles under salt-induced aggregation conditions. In the presence (w/w, 5\%) of the low-molecular-weight PAA (MW 2000 $\mathrm{g} / \mathrm{mol}$ ), a decrease of $\overline{\mathrm{d}}_{\mathrm{z}}$ value down to $0.65 \mu \mathrm{m}$ is now observed for montmorillonite aggregates. On the other hand, theaggregatesize of PVP-modified montmorillonite samples remains high. A $\bar{d}_{z}$ value of $4 \mu \mathrm{m}$ can becal culated for PVP (MW $44000 \mathrm{~g} / \mathrm{mol}$ )-modified montmorillonite (w/w, 5\%) sample. For comparison, in a salt-free water solution, $\overline{\mathrm{d}}_{\mathrm{z}}$ values of $0.45 \mu \mathrm{m}$ arecal culated for unmodified and PAA-modified montmoril lonite particles. In the case of PVP (MW $44000 \mathrm{~g} / \mathrm{mol}$ )-modified montmorillonite particles, a $\overline{\mathrm{d}}_{\mathrm{z}}$ value of $0.75 \mu \mathrm{m}$ is also calculated.

Modeling Results. The permeability properties of the polymer-modified clay films can bethus modeled according to these salt and polymer effects on particle size.

In the case of PVP modification, the variation of the average hydrodynamic particle diameter can be related to the flocculating effect of PVP. At low PVP adsorbed amounts, a partial overlapping of the platelets along the major axis A can be observed. A horizontal deposition and a concomitant increase of the A/B axial ratioaretherefore parameter variations which lengthen the interparticle diffusing path for $\mathrm{Fe}(\mathrm{CN})_{6}{ }^{3-}$ ions. The molecular weight dependence of the shape factor $\alpha$ also shows that this 
band-type network of particles is favored by PVP of high molecular weights which flocculate montmorillonite particles more easily by a bridging mechanism than a PVP of low molecular weight.

In the presence of a low-molecular-weight PAA (MW $2000 \mathrm{~g} / \mathrm{mol}$ ), a decrease of the sedimentation volume al so supposes a better packing of themontmorilloniteparticles. However, as shown by the PCS results, the aggregatesize of the particle in $0.2 \mathrm{M} \mathrm{NaCl}$ is limited after interaction with thelow mol ecular weight PAA. This probably results from an el ectrostatic stabilization due to the screening of the positively charged montmorilloniteedgesurface which otherwisefavors aggregations through edge interactions. A slight increase of the negative electrophoretic mobility also confirms the overall negativate trend of the montmorilloniteparticles in thepresence of PAA. ${ }^{50}$ This surface chargehomogeneity would favor a more parallel al ignment of theindividual montmorillonite platelets in a condensed film phase. Indeed, X-ray diffraction results ${ }^{22,53}$ have shown that a highly ordered parallel alignment for clay platel ets can beobserved in the presenceof other oxyanions such as phosphate compounds which interact in a similar way through specific bindings at the edge of clay minerals. ${ }^{48} \mathrm{~A}$ stacking of clays platelets in straight columns rather than in a random or zigzag columns, Figure 10, has been proposed from the XRD results. In the case of theCME modified by PAA MW $2000 \mathrm{~g} / \mathrm{mol}$, thediminution of theshapefactor $\alpha$ in Table 1 can also beassociated with the formation of close-packing domain structures with a lower $A / B$ axial ratio. Thus, the negatively repelling charged surfaces of the particlequasicrystallinestructure would delimit shorter interparticle diffusing paths to the electrode surface for $\mathrm{Fe}(\mathrm{CN})_{6}^{3-}$.

\section{Conclusions}

This voltammetric study of the montmorillonite clay film permeability not only shows theimportance of a saltdependent film porosity but also supports the presence of occluded clay domains. The modeling of the diffusioncontrolled transport of $\mathrm{Fe}(\mathrm{CN})_{6}{ }^{3-}$ is based on macroscopic

(53) Tateyama, H.; Scales, P. J .; Ooi, M.; Nishimura, S.; Rees, K.; Healy, W. T. Langmuir 1997, 13, 2440.
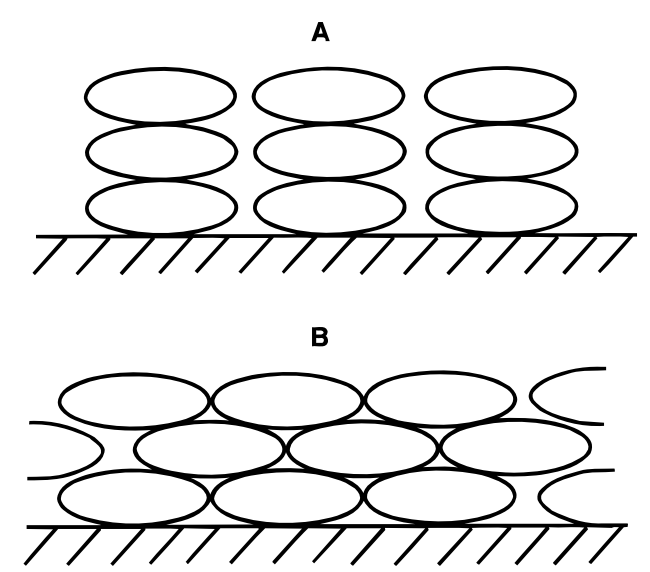

Figure 10. Models for stacking oblate spheroids in straight column (A) or in zigzag column (B).

sedimentation data which allow an effective porosity of the clay film to be approached. Transport through a montmorillonitelayer is alsolimited by the heterogeneity of the clay film due to particles formed from stacking platelets which exclude permeant anions. During the swelling process, the arrangement of these less flexible particles than single montmorillonite platelets creates larger pores. The presence of adsorbed organic polymers can affect the orientations and axial ratios of these particles in different ways depending on their nature, concentrations and molecular weights. This may al ready result in the establishment of preferential pathways ${ }^{54}$ via interparticles governing anion transport. Thus, voltammetric results can give some insights into the behavior of swelling clay in soils where interactions with electrolytes and organic matter as well as drying-weting cycles are known to affect the soil permeability through the development of preferential pathways.

Acknowledgment. Thanks are due to C. Walraf for technical assistance.

\section{LA990550E}

(54) Yaron, B.; Calvet, R.; Prost, R. Soil Pollution; Springer: Berlin, 1996; Chapter 8. 